\title{
Endothelial Progenitor Cells (EPCs) Mobilized and Activated by Neurotrophic Factors May Contribute to Pathologic Neovascularization in Diabetic Retinopathy
}

\author{
Xialin Liu, ${ }^{*}$ Yongjun Li, ${ }^{\dagger}$ Yizhi Liu, ${ }^{*}$ Yan Luo, ${ }^{*}$ \\ Dingding Wang, ${ }^{*}$ Brian $\mathrm{H}$. Annex, ${ }^{\ddagger}$ \\ and Pascal J. Goldschmidt-Clermont ${ }^{\S}$ \\ From the Zhongshan Ophthalmic Center," State Key Laboratory of \\ Ophthalmology, Sun Yat-Sen University, Guangzhou, China; the \\ Department of Vascular Surgery, ${ }^{\dagger}$ Peking Union Medical College \\ Hospital, Chinese Academy of Medical Sciences and Peking Union \\ Medical College, Beijing, China; the Department of Medicine, ${ }^{\neq}$ \\ University of Virginia, Charlottesville, Virginia; and the University of \\ Miami Leonard M. Miller School of Medicine,, Miami, Florida
}

Diabetic retinopathy is characterized by pathological retinal neovascularization. Accumulating evidence has indicated that high levels of circulating endothelial progenitor cells (EPCs) are an important risk factor for neovascularization. Paradoxically, the reduction and dysfunction of circulating EPCs has been extensively reported in diabetic patients. We hypothesized that EPCs are differentially altered in the various vasculopathic complications of diabetes mellitus, exhibiting distinct behaviors in terms of angiogenic response to ischemia and growth factors and potentially playing a potent role in motivating vascular precursors to induce pathological neovascularization. Circulating levels of EPCs from diabetic retinopathy patients were analyzed by flow cytometry and by counting EPC colony-forming units, and serum levels of neurotrophic factors were measured by enzyme-linked immunosorbent assay. We found increased levels of nerve growth factor and brainderived neurotrophic factor in the blood of diabetic retinopathy patients; this increase was correlated with the levels of circulating EPCs. In addition, we demonstrated that retinal cells released neurotrophic factors under hypoxic conditions to enhance EPC activity in vitro and to increase angiogenesis in a mouse ischemic hindlimb model. These results suggest that neurotrophic factors may induce neoangiogenesis through EPC activation, leading to the pathological retinal neovascularization. Thus, we propose that neovascularization in the ischemic retina might be regulated by overexpression of neurotrophic factors. (Am J Pathol 2010, 176:504-515; DOI: 10.2353/ajpath.2010.081152)
Diabetic retinopathy (DR), the most frequent ocular vascular complication of diabetes mellitus (DM), involves the aberrant formation of blood vessels in response to oxygen deprivation in the retina. The mechanisms governing this aberrant neovascularization during DR are still being elucidated. Since Asahara et al first described the presence of circulating endothelial progenitor cells (EPCS) in 1997, ${ }^{1}$ accumulating evidence has indicated that bone marrow-derived EPCs are involved in angiogenesis of ischemic tissues, including ischemic retina. ${ }^{2-7}$ High levels of circulating EPCs are considered to be an important risk factor for pathological neovascularization. ${ }^{8}$ Angiogenic factors, such as vascular endothelial growth factor (VEGF), erythroprotein (EPO), and stromal cell-derived factor-1 (SDF-1), fibroblast growth factor, and platelet-derived growth factor, are potent stimuli for mobilization and homing of stem cells or progenitors to ischemic tissues. , $7,9-14^{-14}$

The reduction and dysfunction of circulating EPCs has been extensively reported in both type 1 and type 2 diabetic patients. ${ }^{15-20}$ Such EPC deficiency is involved in several clinical conditions characterized by high cardiovascular risk, as well as in the peripheral vascular complications of diabetes patients. The low number and dysfunctionality of EPCs are believed to be indicators for the severity of diabetic vasculopathy, ${ }^{18}$ which is characterized by a poor angiogenic response in ischemic myocardium and limbs. ${ }^{17,21,22}$ Paradoxically, DR, which occurs in both types 1 and $2 \mathrm{DM}$, is characterized by enhanced angiogenesis and significant retinal neovascularization in response to retinal ischemia. ${ }^{23}$ Lee et $\mathrm{al}^{5}$ demonstrated that high levels of EPCs, as defined by CD34-positive mononuclear cells, may

\footnotetext{
Supported by grants from National Natural Science Foundation of China to Xialin Liu (30740078 and 30500554) and Yongjun Li (30772114).

The authors declare no competing interests.

Accepted for publication September 9, 2009

Supplemental material for this article can be found on http://ajp. amjpathol.org.

Address reprint requests to Xialin Liu, M.D., Ph.D., Zhongshan Ophthalmic Center, Sun Yat-sen University, Guangzhou, China, 510060 E-mail: xialinliu02@hotmail.com; and Pascal J. Goldschmidt-Clermont, M.D., University of Miami, Leonard M. Miller School of Medicine, Miami, Florida, 33101. E-mail: PGoldschmidt@med.miami.edu.
} 
be involved in neovascularization in DR. Subsequently, Fadini et al ${ }^{23}$ reported that patients with DR had enhanced endothelial differentiation of circulating progenitors characterized by a high CD34+KDR+ proportion, in contrast to patients with DM with peripheral arterial disease (PAD), who showed poor endothelial differentiation. These findings led to the hypothesis that EPCs may be differentially altered in the various vasculopathic complications of DM, exhibiting distinct behaviors in terms of angiogenic response to ischemia. Furthermore, specific growth factors may play a potent role in mobilizing and activating vascular precursors to induce pathological neovascularization. ${ }^{24-26}$

The retina is a neuronal tissue comprised of neurons and glia. Recent studies have shown that the neurons and glial cells may interact with blood vessels to contribute to pathological neovascularization by creating a particular cytokine milieu. ${ }^{27,28}$ There is increasing interest in understanding the process of neuronal driven angiogenesis. ${ }^{29-32}$ It has been demonstrated that neurons secrete growth factors, such as platelet-derived growth factor and VEGF, to guide angiogenic sprouting, particularly in low oxygen conditions. ${ }^{28,33-37}$ The introduction of cytokines, including VEGF, can enhance mobilization of endothelial progenitors, and/or proangiogenic hematopoietic cells, to ischemic limbs to promote the re-endothelialization process. ${ }^{2,38}$ Increased serum concentrations of VEGF, achieved by adenoviral vector transfection or injection of naked DNA coding for VEGF, significantly increase the number of circulating EPCs, in both animal and human subjects. ${ }^{39,40}$ Moreover, some neurotrophins known for their roles in mediating axonal pathfinding also play critical roles in angiogenesis regulation. ${ }^{30,41-43}$ Neurotrophic factors (NTFs), such as nerve growth factor (NGF) and brain-derived neurotrophic factors (BDNF) have been found to exert proangiogenic effects, not only by directly affecting endothelial cells, but also by recruiting bone marrow-derived cell precursors. NGF and BDNF, known neurotrophins, have recently been identified as novel strong angiogenic molecules that target endothelial cells and in the vascular system in general. ${ }^{44-49}$

The finding that neural guidance molecules influence blood vessel growth has suggested that neurotrophic molecules may regulate pathological angiogenesis. We hypothesized that neuronal cells from the retina may release specific NTFs, such as NGF, BDNF, and glial cell line-derived neurotrophic factor (GDNF), in response to hypoxia factors that may couple with other angiogenic factors like VEGF to enhance the recruitment of EPCs or enhance EPC activity, thus contributing to pathological alterations in DM. In our study, we quantified circulating EPCs by two methods: CD34+CD133+ double positive cells measured by flow cytometry and EPC-colony forming unit (CFU) assay. We focused on CD34/CD133 double-positive cells, rather than CD34-positive cells, as studies have suggested that they provide for more specific selection of progenitor cells. ${ }^{10,50,51}$ Furthermore, we investigated whether retinal cells under hypoxia can influence the migration and differentiation of EPCs by releasing cytokines in vitro. We also studied angiogenesis in a mouse ischemic hindlimb model after injection of retinal cell-derived conditioned medium obtained under hypoxic conditions. Our results showed that retinal neuronal tissue releases neurotrophic factors that may play an important role in regulating new vessel growth.

\section{Materials and Methods}

\section{Patients, Subjects, and Sample Collection}

All studies were performed on patients with the approval of the Hospital Ethics Committee of Zhongshan Ophthalmic Center. We enrolled 20 type 2 diabetic patients with $\mathrm{DR}, 20$ type 2 diabetic patients with PAD, and 20 ageand sex-matched non-diabetic healthy controls (No-DM) in the study. After overnight fasting of at least 12 hours, $3 \mathrm{ml}$ of venous blood was drawn from all patients and controls. Samples were immediately centrifuged at $3000 \times g$ for 10 minutes to obtain serum and stored at $-80^{\circ} \mathrm{C}$. Additionally, $12 \mathrm{ml}$ of blood were drawn from DR patients and healthy controls to obtain mononuclear cells for flow cytometry analysis and EPC colony culture within 6 hours. We did not count EPCs for patients with PAD-DM, because such studies have been reported ${ }^{17,18,23,52,53}$ Diabetic retinopathy was defined by a dilated and comprehensive eye examination and high-quality stereoscopic photography by a certified ophthalmologist and was confirmed by fluoroangiography. Participants met the following DR ocular entry criteria: 1) Early Treatment Diabetic Retinopathy Study (ETDRS) retinopathy severity level from severe nonproliferative DR to proliferative retinopathy (PDR), 2) no history of panretinal photocoagulation associated with DR, and 3) no evidence of glaucoma or other recorded eye disease. As the referenced method by Lynons, ${ }^{54}$ the severe nonproliferative DR and PDR was defined with unilateral "severe" nonproliferative diabetic retinopathy (severe hemorrhages in four quadrants, venous beading in at least two quadrants, moderately severe IRMA in at least one quadrant) or worse. The EPC level as well as the blood concentration of neurotrophins was analyzed separately for the pre-proliferative retinopathy patients and PDR patients in the primary study. Since there was no significant difference in EPC, NGF, and BDNF levels between the severe preproliferative group and PDR group, we grouped the severe nonproliferative DR and PDR together as diabetic retinopathy group in this study. PAD was defined clinically by the symptoms of claudication, pain at rest, and, in some cases, need for lower limb amputation. We confirmed the diagnosis of PAD with ankle brachial index less than 0.9 plus ultrasound or CT angiography. Ankle brachial index is the ratio between ankle arterial pressure and humeral arterial pressure; ankle brachial index $<0.9$ indicates arterial insufficiency in the lower limb. Participants were excluded if they had: 1) a history of significant heart disease (including unstable angina, acute coronary syndrome, myocardial infarction, arrhythmia, or history of a coronary revascularization procedure within the last year); 2) uncontrollable hypertension $>160 / 100 \mathrm{mmHg}$, stroke in the previous 2 years; 3 ) history of renal transplantation involving immune suppressant therapy; 4) immunodeficiency; or 5) anemia with hemoglobin $<10 \mathrm{~g} / \mathrm{dl}$. Further exclusion criteria included the presence of active or chronic infection, operations or trauma within the previous 6 months, evidence for malignant disease, renal or hepatic insufficiency, and mental retardation. 


\section{Flow Cytometry Analysis}

We defined EPCs as CD133/CD34 double-positive cells. The number of EPCs was assessed by flow cytometry analysis as previously reported. ${ }^{50,55}$ Briefly, mononuclear cells were isolated from $12 \mathrm{ml}$ of peripheral venous blood by density gradient centrifugation using Ficoll-Paque (Amersham Biosciences, Piscataway NJ). One million cells per sample were stained with PE-Cy7-conjugated mouse antihuman CD34 (clone 8G12, BD Biosciences, Pharmingen, San Jose, CA) antibody, and allophycocyanin-conjugated mouse anti-human CD133 (AC133, Miltenyi Biotec, Bergisch Gladbach, Germany) antibody for 30 minutes at $4^{\circ} \mathrm{C}$. A human Fc receptor blocker was added to each sample. Samples were incubated for 15 minutes before addition of each of the antibodies and then incubated for 20 minutes at room temperature. Dead cells were identified by propidium iodide staining and were excluded from analysis. The stained cells were examined with a dual laser FACS Vantage (Becton Dickinson) flow cytometry. Flow cytometry data were analyzed using the Macintosh CELL Quest software program (Becton Dickinson).

\section{EPC Culture and CFUs Counts}

EPC culture-CFU counts were performed using previously reported methods. ${ }^{19,20,56-58}$ In brief, the isolated mononuclear cells were washed twice with phosphate buffered saline containing $2 \%$ fetal bovine serum (FBS) and then resuspended in a growth medium comprised of Medium 199 (Gibco) supplemented with 20\% FBS, 100 $\mathrm{U} / \mathrm{ml}$ penicillin, and $100 \mathrm{~g} / \mathrm{ml}$ streptomycin (Gibco). A total of 10 million cells, with 5 million cells per well, were plated in six-well fibronectin-coated dishes (Biocoat, Becton Dickinson Labware, Bedford, MA) and incubated at $37^{\circ} \mathrm{C}$ in humidified $5 \% \mathrm{CO}_{2}$. After being cultured for 48 hours, the nonadherent cells were replated with 1 million cells per well in 24-well fibronectin-coated dishes (Biocoat, Becton Dickinson Labware, Bedford, MA) to avoid contamination from mature endothelial cells. The cells were supplemented with new growth media 4 days after replating. Seven days after replating, the numbers of CFUEPCs were counted in a minimum of four wells by an observer unaware of the patient's clinical status. A colony was defined as a central cluster of round cells with multiple spindle-shaped cells radiating from the periphery, as previously reported. ${ }^{20}$ It has been reported that there are two types of EPCs colonies (early EPCs and the late EPCs colony) and the late EPCs colony represented the true EPC colony, ${ }^{57,58}$ we further cultured cells for 4 to 6 weeks and performed the late EPC colony culture following Hur's method. The late EPC colony had different morphology and growth pattern. They appeared in 2 or 4 weeks after plating, and showed cobblestone appearance.

\section{Retinal Cells Isolated and Cultured under Hypoxic Conditions}

Postmortem eyes were obtained from the Zhongshan Eye Bank (Guangzhou, China) 6 to 12 hours after death.
Primary cultures of human retinal glial cells were prepared using standard methods. ${ }^{59-62}$ Briefly, the neural retina was separated from the pigment epithelium, diced into pieces and dissociated by pipetting in $4 \mathrm{ml}$ culture medium. The resulting cell suspension was centrifuged at $800 \times g$, resuspended in culture medium, and seeded into dishes coated with fibronectin-collagen (Biological Research, ljamsville, MD) in Dulbecco's modified Eagle's medium with $5.5 \mathrm{mmol} / \mathrm{L}$ glucose, $10 \%$ fetal bovine serum, $1 \%$ penicillin-streptomycin, and $2 \mathrm{mmol} / \mathrm{L} \mathrm{L-glu-}$ tamine. After 2 to 3 days of culture, the medium was replaced to remove floating debris and vascular fragments. The cultures were fed with fresh medium every 3 days until confluence, usually 3 to 4 weeks. When confluent, cells were passaged. When early-passaged (passages 1 to 3 ) retinal cells were cultured in 10\% FBSDulbecco's Modified Eagle Media (DMEM) for 3 to 4 days until $60 \%$ to $80 \%$ confluence, they were washed and fed with fresh medium without FBS and placed in the incubator either at normoxic (75\% N2, 5\% CO2, 20\% O2) conditions or hypoxic conditions (90\% N2, 5\% CO2, 5\% O2) for 48 hours for further experiments.

\section{Measurement of Neurotrophic Factors Concentration in Serum and Culture Supernatant}

Serum levels of VEGF, NGF, BDNF, GDNF, EPO, and SDF-1 were measured using commercially available human VEGF, b-NGF, BDNF, and GDNF sandwich enzymelinked immunosorbent assays kits (VEGF, EPO, and SDF-1, from R\&D Systems, Minneapolis, MN; b-NGF, BDNF, and GDNF all from Promega, Madison, WI). All procedures were performed according to the manufacturer's instructions. Similarly, the levels of NGF, BDNF, and GDNF in the retinal cell culture medium supernatant under hypoxic conditions were measured. Each sample $(100 \mu l)$ was run in duplicate and compared with a standard curve. All samples were assigned a random number and run without knowledge of the donor's health status. After data were compiled, the sample classifications were revealed. The sample concentrations in each plate were calculated according to standard curves and dilution factors.

\section{EPC Migration Assay in a Transwell Co-Culture System}

In vitro EPC migration was assayed in a modified Boyden chamber (transwell) co-culture system, as previously described. ${ }^{63,64}$ A Transwell chamber (Costar Co., Cambridge, MA) having a polycarbonate filter with a $6.5 \mathrm{~mm}$ diameter and $8 \mu \mathrm{m}$ pore-size was used for this assay. The freshly collected $1 \times 10^{4}$ CD34+CD133+EPCs were immediately placed in the upper chamber in each well. These cells were co-incubated with feeding cells (either confluent retinal cells or, human microvascular endothelial cell for control) in the lower chamber under hypoxic conditions in the transwell co-culture system; we then 
Table 1. Characteristics of the Patients

\begin{tabular}{|c|c|c|c|c|}
\hline & $\begin{array}{c}\text { DR } \\
n=20\end{array}$ & $\begin{array}{c}\text { DM-PAD } \\
n=20\end{array}$ & $\begin{array}{c}\text { Normal control } \\
n=20\end{array}$ & $P$ value \\
\hline Age (yr) & $69.5 \pm 7.5$ & $65.8 \pm 6$ & $67.7 \pm 4.5$ & NS \\
\hline $\operatorname{Sex} M(n / \%)$ & $9(45 \%)$ & $12 /(60 \%)$ & $10 /(50 \%)$ & NS \\
\hline Duration of diabetes (yr) & $11.3 \pm 5.0$ & $14.50 \pm 6.0$ & 1 & \\
\hline BMl $\left(\mathrm{kg} / \mathrm{m}^{2}\right)$ & $24.2 \pm 1.2$ & $23.7 \pm 3.1$ & $23.2 \pm 2.3$ & NS \\
\hline \multicolumn{5}{|l|}{ Laboratory testing } \\
\hline Fasting glucose (mmol/L) & $7.2 \pm 4.3$ & $7.9 \pm 2.8$ & $5.1 \pm 1.2^{*}$ & $<0.01$ \\
\hline $\mathrm{HbA} 1 \mathrm{c}(\%)$ & $8.5 \pm 1.2$ & $9.2 \pm 1.7$ & I & \\
\hline Total cholesterol mg/dl & $184.6 \pm 3.8$ & $187.2 \pm 5.2$ & $180.0 \pm 10.5$ & NS \\
\hline LDL-C, mg/dl & $114.2 \pm 5.2$ & $116.2 \pm 3.4$ & $110.3 \pm 4.8$ & NS \\
\hline $\mathrm{HDL}-\mathrm{C}, \mathrm{mg} / \mathrm{dl}$ & $47.2 \pm 1.6$ & $45.6 \pm 1.8$ & $51.2 \pm 1.3$ & NS \\
\hline Triglycerides, mg/dl & $133.8 \pm 11.2$ & $145.8 \pm 9.6$ & $133.2 \pm 10.5$ & NS \\
\hline \multicolumn{5}{|l|}{ Clinical history } \\
\hline Hypertension & 13 & 15 & 13 & NS \\
\hline CAD & 9 & 12 & 10 & NS \\
\hline Smoker & 3 & 5 & 5 & NS \\
\hline \multicolumn{5}{|l|}{ Medications } \\
\hline Insulin & 5 & 7 & 1 & \\
\hline Oral Antidiabetics & 20 & 20 & l & \\
\hline TZDs & 5 & 7 & i & NS \\
\hline Statins & 12 & 11 & 13 & NS \\
\hline ACE-inhibitors & 3 & 4 & 4 & NS \\
\hline Other hypotensive drugs & 11 & 13 & 10 & NS \\
\hline
\end{tabular}

NS: not statistic significant; dashes denote not applicable.

observed the migration of the EPCs from the upper chamber into the lower chamber through the $8 \mu \mathrm{m}$ pore-size filter by counting the retained cells in the upper chamber in five separate high-power fields.

\section{Evaluation of EPC Differentiation with Immunofluorescence Staining and Capillary-Like Tube Formation Assay on Matrigel}

We cultured EPCs in 24-well plate under normoxic conditions in M199 medium (adding stem cell cytokine cocktails: $10 \mathrm{ng} / \mathrm{ml}$ IL-6, $1 \mathrm{ng} / \mathrm{mlGM}-\mathrm{CSF}, 30 \mathrm{ng} / \mathrm{mlSF}, 20$ $\mathrm{ng} / \mathrm{ml}$ Flt3L, $100 \mathrm{ng} / \mathrm{ml}$ Tpo). Samples were divided into two groups, one with and one without retinal-cell conditioned medium (obtained from the retinal cell culture medium generated under hypoxic conditions) added every 2 days for 2 weeks. Effects of conditioned media on EPCs were evaluated by immunofluorescence staining with antibodies to VEGFR2 and to VE-cadherin, which are established mature endothelial cell surface markers to identify EPC differentiation. ${ }^{19}$ Briefly, cells were fixed in $4 \%$ paraformaldehyde in PBS and blocked for 30 minutes with $2 \%$ bovine serum albumen in PBS, incubated sequentially for 1 hour with primary antibodies against VEGFR2 (1:50) and VE-Cadherin (1:50) (R\&D Systems). Secondary antibodies (Alexa fluoro-conjugated) and Ho3444 for DNA staining (Molecular Probes) were used at 1:250 to 1:500, respectively and incubated for 30 minutes. Cells were then washed and analyzed by fluorescence microscopy.

Tube formation assay was adapted from the conventional method ${ }^{57,65} ; 150 \mu \mathrm{m}$ Matrigel (BD Bioscience, Bedford, MA) basement membrane matrix was added to 96-well culture plates and incubated at $37^{\circ} \mathrm{C}$ until gelation occurred. Cultured EPCs $\left(1 \times 10^{4}\right.$ cells $)$ were resus- pended and added to each well in $100 \mu$ l EGM-2 media containing 15\% FBS, 1\% Penicillin, Streptomycin Andamphotericin (PSA). Twelve hours later, capillary tube formation was assessed via phase contrast microscopy.

\section{Evaluation of Angiogenesis in Ischemic Hindlimb after Injection of Retinal Conditioned Medium}

As previously reported, ${ }^{66} 20$ high-fat-diet-fed DM C57B6 mice (obtained from Institute of laboratory animal sci-
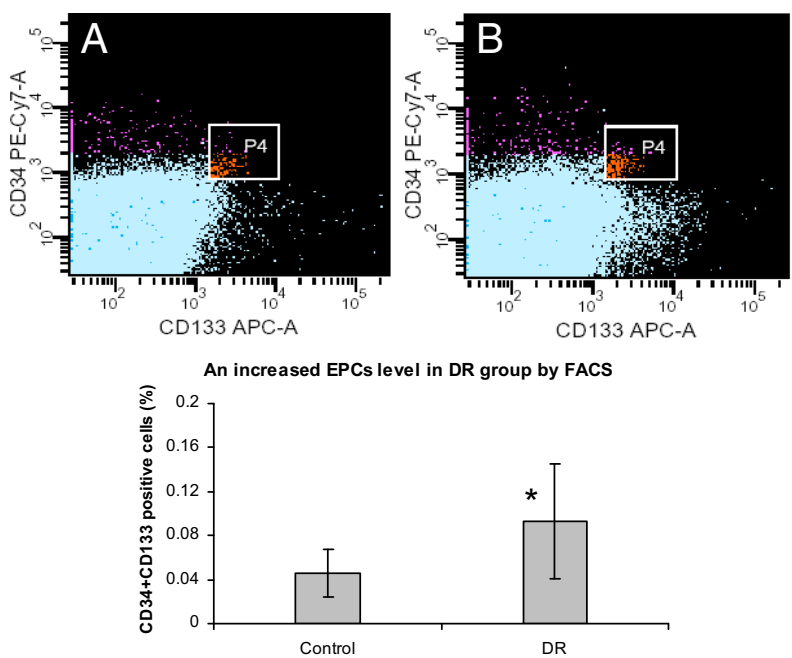

Figure 1. Increased circulating EPC levels in DR group versus controls shown by flow cytometry analysis. Representative flow cytometry patterns from (A) a normal control and (B) a DR patient. EPCs were defined with positive expression for both CD133-allophycocyanin (forward scatter) and CD34-Pe-cy7 (side scatter). P4 (window) represents CD34 AC133 double positive populations. The graph below the photographs displays the statistical analysis comparison, which indicates an increased percentage of EPCs in DR group (DR: $0.093 \pm 0.052 \%$, vs. control: $0.045 \pm 0.02 \%, n=$ $\left.20,{ }^{*} P<0.01\right)$. 

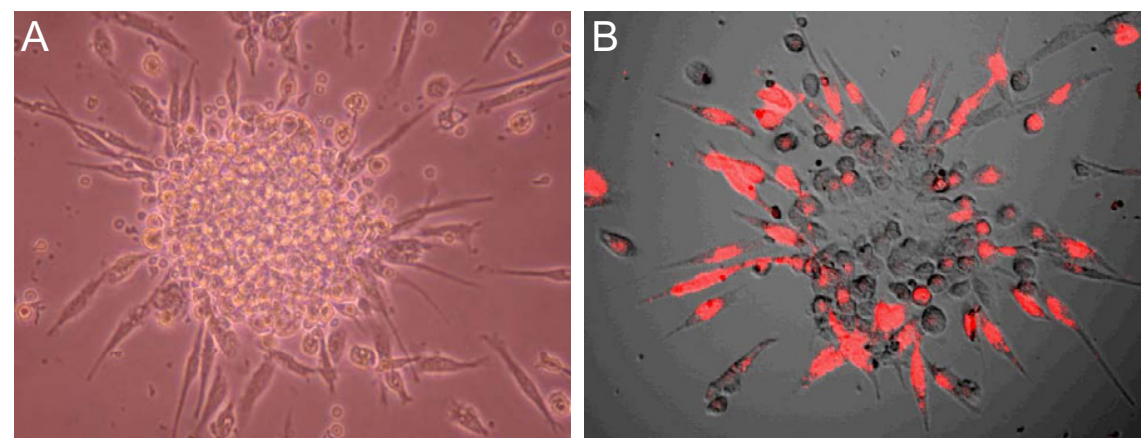

Figure 2. Representative EPC-CFU. A: Phase contrast microscopy showing the early EPC-CFU in culture. The colony is seen as a central cluster of round cells with multiple spindle-shaped cells radiating from the periphery. B: VEGFR2-positive staining (red) seen by confocal microscopy.

ences, Chinese Academy of Medical Sciences \& Peking Union Medical College) underwent unilateral femoral artery ligation and excision to surgically induce hindlimb ischemia. Ten days later, mice were randomly assigned to receive retinal-cell-conditioned medium or vehicle control (DMEM) ( $n=10 /$ group) injection into the ischemic gastrocnemius muscle (daily injection for 7 days). The preparation for the retinal-cell-conditioned medium is described in the section "Retinal Cells Isolated and Cultured under Hypoxic Conditions." Briefly, the early passaged retinal cells were fed with fresh DMEM without FBS and placed in the incubator at hypoxic conditions (90\% N2, $5 \% \mathrm{CO} 2,5 \% \mathrm{O} 2)$ for 48 hours. The supernatant medium was collected after filtrating for injection. The levels of NTFs in the retinal-cell-conditioned medium have been tested.

Blood flow was examined before and at 20 days after injection with Laser Doppler Perfusion Imaging system (PERIMED, Stockholm, Sweden). The results were expressed as a ratio of perfusion in the ischemic versus normal limb. Changes in perfusion were calculated as the ratio at day 20 minus the baseline ratio (ten days post surgery) Mice were sacrificed and gastrocnemius muscle was harvested for pathological examination. Endothelial cells were identified by immunohistochemical staining using a rat anti-mouse CD31 antibody (1:200 dilution, Serotec, Raleigh, NC). Capillary density was measured by counting five random high-power (magnification $\times 200$ ) fields, or a minimum of 200 fibers from each sample on an inverted light microscope, and expressed by the number of CD31 positive cells per $\mathrm{mm}^{2}$ or per fiber to exclude any potential differences induced by muscle edema or atrophy. Area was measured with an $\mathrm{NIH} \mathrm{Im-}$ age analysis system (Image $\mathrm{J}$ ).

\section{Statistical Analysis}

The data were summarized in the form of means \pm SEM. We performed a statistical analysis by using SAS (SAS Institute Inc., Cary, NC). Group heterogeneity was assessed by running the Duncan's multiple range test for the levels of NTFs in three groups: DR, DM-PAD and non-diabetic control. All reported $P$ values are two-sided. A level of $P<0.05$ was accepted as statistically significant. The Spearman's rank correlation coefficients and the corresponding $P$ values of correlation tests were calculated for the pairs of variables. Then we applied a forward stepwise multiple linear regression model to select the factors correlated with the response EPC significantly. To demonstrate and quantify the associations of EPC, NGF, or/and BDNF with DR, we performed logisticregression analyses with disease status (DR or non-diabetic controls) as the response variable and other factors as dependent variables.

\section{Results}

\section{Patient Demographic Data}

The average ages of DR patients, PAD patients, and No-DM healthy controls were, respectively, $69.5 \pm 7.5$,

Table 2. The Serum Levels of Growth Factors and EPCs

\begin{tabular}{|c|c|c|c|}
\hline & Control & DR & PAD \\
\hline NGF & $243.56 \pm 98.80$ & $562.45 \pm 125.78^{*}$ & $248.47 \pm 102.32$ \\
\hline Duncan's multiple range test & B & $A$ & B \\
\hline VEGF & $365.61 \pm 87.96$ & $602.29 \pm 138.01^{\star *}$ & $340.67 \pm 142.82$ \\
\hline Duncan's multiple range test & B & $A$ & B \\
\hline BDNF & $16.76 \pm 5.36$ & $30.59 \pm 9.93^{*}$ & $13.71 \pm 4.19$ \\
\hline Duncan's multiple range test & B & A & B \\
\hline EPO & $13.15 \pm 3.20$ & $11.89 \pm 2.97$ & $11.00 \pm 3.95$ \\
\hline Duncan's multiple range test & A & $A$ & $A$ \\
\hline SDF_1 & $1105.94 \pm 341.74$ & $1305.14 \pm 455.97$ & $1107.99 \pm 432.33$ \\
\hline Duncan's multiple range test & $A$ & $\bar{A}$ & $A$ \\
\hline EPC & $0.05 \pm 0.02$ & $0.09 \pm 0.05^{\star \star}$ & \\
\hline Duncan's multiple range test & B & A & \\
\hline
\end{tabular}

Values are mean \pm standard deviation. ${ }^{*} P<0.05,{ }^{* *} P<0.01$.

Results with the same letters indicate no statistical difference.

GDNF was undetectable. 
A

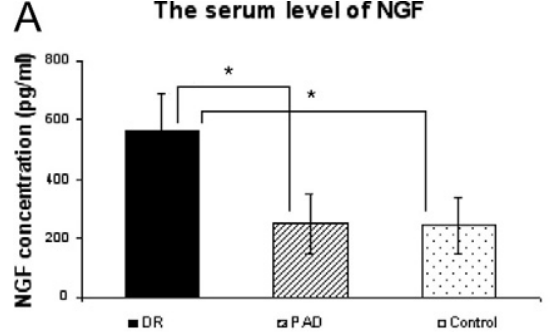

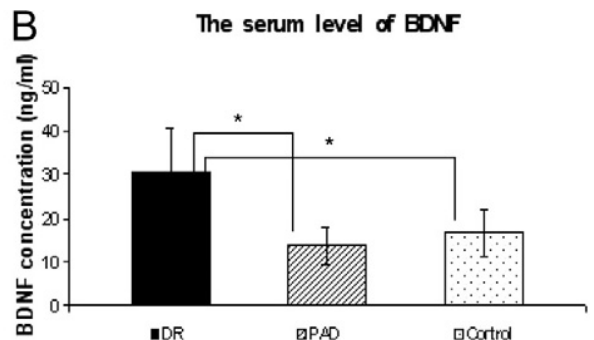

Figure 3. NGF and BDNF serum levels. A: Increased NFG level in DR group as compared with other groups: $562.45 \pm 125.78$ (DR) versus $248.47 \pm 102.32(\mathrm{PAD})$ versus $243.56 \pm 98.80$ (control). B: Increased BDNF level in DR group as compared with other groups: $30.59 \pm 9.93$ $(\mathrm{DR})$ versus $13.71 \pm 4.19(\mathrm{PAD})$ versus $16.76 \pm$ 5.36 (control). ${ }^{*} P<0.05$
$65.8 \pm 6$, and $67.7 \pm 4.5$. Female and male patients were included in each group. There was no significant difference in age/sex ratio among the diabetic patients and the control group. The mean diabetes duration was $11.3 \pm$ 5.0 years in DR group, and $14.50 \pm 6.0$ years in PAD-DM group. Patients characteristics are summarized in Table 1. The analysis indicated that there was no significant difference in demographic characteristics in different groups such as age, gender, the prevalence of hypertension, cardiovascular disease, smoking, and use of drugs such as statins and Thiazolidinediones (TZDs).

\section{Increased CD34+CD133+EPC Cells and Enhanced CFU-EPCs in DR Group}

CD34+/CD133+ double-positive cells were identified and analyzed by flow cytometry, as illustrated in Figure 1, A-B. Statistical analysis showed increased levels of circulating CD34+/CD133+ double-positive EPCs in the DR group as compared with nondiabetic controls (DR: $0.0933 \pm 0.052 \%$, vs control: $0.045 \pm 0.02 \%, P<0.001)$. Figure 2 shows the typical early EPC colonies in culture (Figure 2A) and its VEGF receptor II positive staining (Figure 2B). DR patients also showed an increase in the early EPC-CFU counts measured by phase contrast microscope ( $7 \pm 4 /$ well versus $3 \pm 2 /$ well). An image of the late EPC colony is included in the supplemental data section (see Supplemental Figure S1 at http://ajp. amjpathol.org).

\section{Serum Levels of Neurotrophic Factors in DR Patients and Correlation Analysis}

Table 2 showed the serum levels of growth factors and EPCs in the three groups: (a) the serum concentrations of NGF, BDNF, VEGF were significantly different between DR and the nondiabetic control groups, but not significantly different between the DM-PAD and control groups; (b) the serum concentrations of SDF-1 and EPO were not different among three groups; Figure 3 indicated that the serum concentration of NGF, BDNF increased in the DR groups as compared with the DM-PAD and nondiabetic control groups; Then, we calculated the Spearman's rank correlation coefficients and the corresponding $P$ values for pairs for variables NGF, BDNF, VEGF, EPO, SDF-1, and EPC, summarized in Table 3. In the last row, the $P$ values indicated that only NGF and BDNF were correlated with EPC significantly. In addition, the correlation between NGF and BDNF was not very strong. Therefore, we could perform a bivariate linear regression analysis with EPC as the dependant variables and NGF and BDNF as the predictors. We found that both BDNF and NGF were still correlated with EPC significantly. Moreover, the R-Squared 0.7404 indicated that the model reasonably fits the data (Table 4). Finally, we used logistic regression method to analyze the data with the presence of DR as the end-point. Since the factors NGF and BDNF are highly correlated with EPC, we did not put them into the model to avoid multicollinearity. Two factors EPC and VEGF were shown to be significantly associated with DR. The results including the Wald statistics and the odd ratios were summarized in supplemental tables S1 and S2 (see Supplemental Tables S1 and S2 at http://ajp. amjpathol.org).

\section{Co-Culture with Retinal Cells under Hypoxic Conditions Enhanced EPC Migration and Conditioned Culture Medium Enhanced EPC Cells Differentiation In Vitro}

In an in vitro transwell co-culture system with confluent retinal glial cells or control human microvascular endothelial cells in the lower chamber under hypoxic conditions for 24 hours, the freshly collected $1 \times 10^{4}$ CD34+CD133+EPCs were immediately put in the upper chamber in each well. After these cells were co-incubated for 6 hours in the transwell with $8 \mu \mathrm{m}$-hole-size filter co-culture system, retinal cells in the lower chamber induced a significantly increased migration of upper chamber EPCs compared with control human microvascular endothelial cells (Figure 4, A-D).

Table 3. Spearman Correlation Coefficients

\begin{tabular}{|c|c|c|c|c|c|c|}
\hline & NGF & VEGF & BDNF & EPO & SDF-1 & EPC \\
\hline NGF & 1.00000 & $-0.08235(P=0.7617)$ & $0.13824(P=0.6097)$ & $0.35000(P=0.1839)$ & $0.43235(P=0.0944)$ & $0.58468(P=0.0174)$ \\
\hline VEGF & $-0.08235(P=0.7617)$ & 1.00000 & $-0.33235(P=0.2085)$ & $0.02647(P=0.9225)$ & $-0.10882(P=0.6883)$ & $0.02798(P=0.9181)$ \\
\hline BDNF & $0.13824(P=0.6097)$ & $-0.33235(P=0.2085)$ & 1.00000 & $-0.17647(P=0.5133)$ & $0.13824(P=0.6097)$ & $0.50368(P=0.0467)$ \\
\hline EPO & $0.35000(P=0.1839)$ & $0.02647(P=0.9225)$ & $-0.17647(P=0.5133)$ & 1.00000 & $0.33529(P=0.2043)$ & $0.10162(P=0.7080)$ \\
\hline SDF_1 & $0.43235(P=0.0944)$ & $-0.10882(P=0.6883)$ & $0.13824(P=0.6097)$ & $0.33529(P=0.2043)$ & 1.00000 & $0.43888(P=0.0890)$ \\
\hline $\mathrm{EPC}^{-}$ & $0.58468(P=0.0174)$ & $0.02798(P=0.9181)$ & $0.50368(P=0.0467)$ & $0.10162(P=0.7080)$ & $0.43888(P=0.0890)$ & 1.00000 \\
\hline
\end{tabular}


Table 4. Multivariate Regression with Dependent Variable: EPC $($ R-square $=0.7404)$

\begin{tabular}{lcc}
\hline & $\begin{array}{c}\text { Parameter } \\
\text { Estimate }\end{array}$ & $P$ value \\
\hline Intercept & -0.13556 & 0.0041 \\
BDNF & 0.00292 & 0.0026 \\
NGF & 0.00024805 & 0.0015 \\
\hline
\end{tabular}

Treatment of EPCs with conditioned media from retinal cell cultures incubated under hypoxic conditions resulted in a marked increase in EPC differentiation, as shown by two representative endothelial cell antibody immunostaining (VEGFR2 and VE-cadherin) (Figure 5, A and B). In addition, conditioned media enhanced the capability of capillary-like tube formation on Matrigel culture, as shown in Figure 5, C and D.

\section{Significantly Increased Neurotrophic Factor Expression in Retinal Cells Cultured under Low Oxygen Conditions in Vitro}

To characterize the content of the conditioned retinal cell medium, which showed marked effect on EPCs, we collected the retinal cell culture medium supernatant under low oxygen conditions (24 hours) to measure the levels of NTPs. As shown in Figure 6, incubation of human retinal cells at low oxygen concentration led to a significant increase in the content of the medium in NTPs, including NGF, BDNF, and GNDF (NGF: $545.68 \pm 120.70 \mathrm{pg} / \mathrm{ml}$ vs. $712.90 \pm 116.78 \mathrm{pg} / \mathrm{ml} P<0.01 ;$ BDNF: $292.00 \pm 92.08$ $\mathrm{pg} / \mathrm{ml}$ vs. $610.03 \pm 148.42 \mathrm{pg} / \mathrm{ml}, P<0.01$; GNDF: $28.94 \pm 8.29 \mathrm{pg} / \mathrm{ml}$ vs. $71.07 \pm 13.44 \mathrm{pg} / \mathrm{ml}, P<0.01)$, when compared with the control cultures incubated under normoxic conditions.

\section{Enhanced Angiogenesis in Ischemic Hindlimb after Injection with Retinal-Cell- Conditioned Medium}

Laser Doppler perfusion imaging was performed before (10 days after surgery) and at day-20 after injection. Before medium injection, the perfusion ratio was similar between the two groups $(0.58 \pm 0.07$ vs. $0.60 \pm 0.05)$. At 20 days after injection, there was a clear and statistically significant change in perfusion ratio with retinal-cell-conditioned medium (0.31 \pm 0.027 vs.0.09 $\pm 0.024, P<$ 0.001 , Figure $7 A$ ). Capillary density in the ischemic gastrocnemius muscle was also significantly higher in the retinal medium versus control-treated mice (552 \pm 38 vs. $406 \pm 25, P<0.01$, Figure 7B). To exclude potential differences induced by muscle edema or atrophy, the capillary-to-muscle, fiber ratio in the ischemic muscle was also measured. Like capillary density, the capillary/ muscle fiber ratio was significantly higher in the retinal medium versus control-treated mice (1.44 \pm 0.04 vs. $1.18 \pm 0.07, P<0.01)$.

\section{Discussion}

We found that circulating CD34+/CD133+ double-positive EPCs were significantly increased in DR groups, as compared with nondiabetic controls. In addition, we found elevated EPC levels and a high concentration of circulating neurotrophins in the DR patients, indicating that EPC, as well as neurotrophin levels in peripheral blood are impacted by the presence of DR. Different methods have been used to determine EPC levels, including labeling with various specific cell surface markers and by counting CFU-EPC in culture. ${ }^{5,10,23}$ We decided to use both approaches and counted the CFUs in EPC culture following Hill's method. ${ }^{20}$ We found a signif-
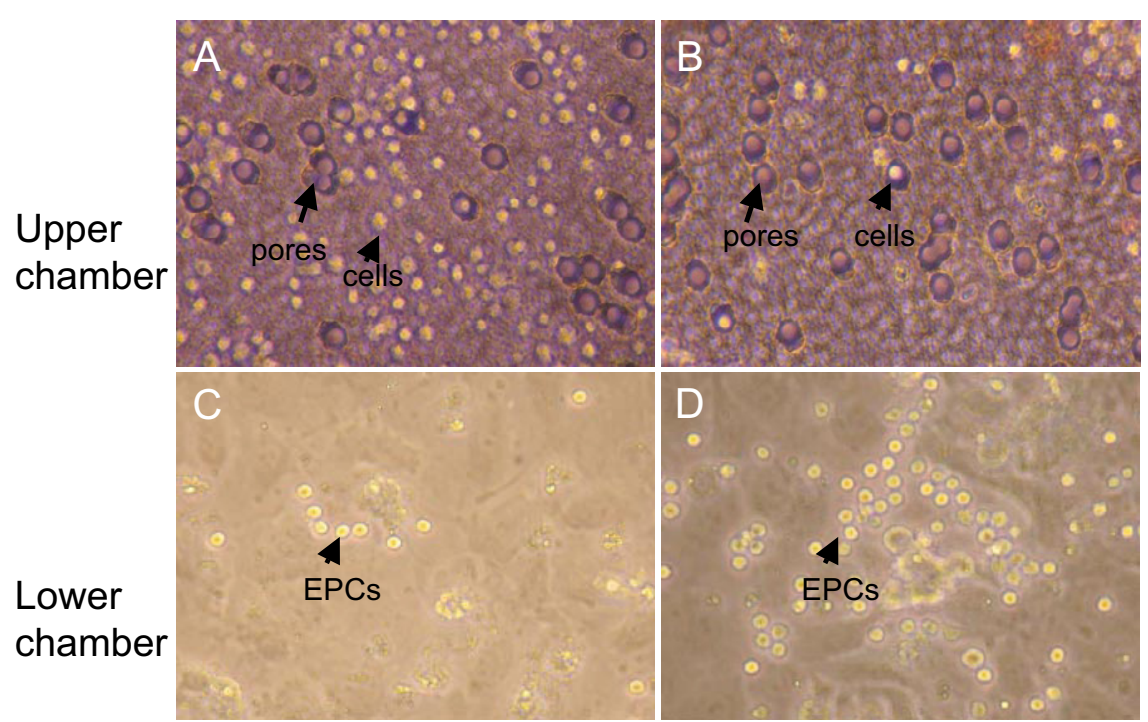

hMVECs cells

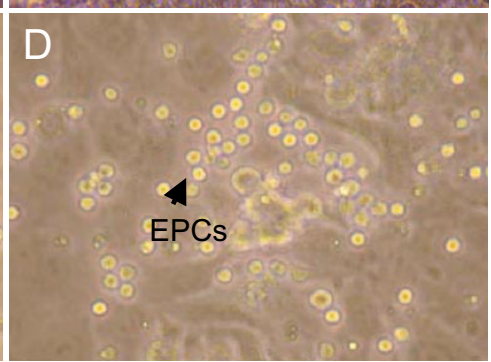

Retinal Cells
Figure 4. Two-chamber co-culture with retinal cells under hypoxic conditions enhances EPC cell migration. In a transwell co-culture system under hypoxic conditions with an $8 \mu \mathrm{m}$ holesize (purple) filter, many cells (yellow) stayed in the upper chamber (A) and few cells passed through the filter to the lower chamber $(\mathbf{C})$ when co-cultured for 6 hours with HMVECs. In contrast, after co-culture with retinal cells, many more EPCs passed through the holes into the lower chamber (D) and fewer cells stay in the upper chamber $(\mathbf{B})$ 

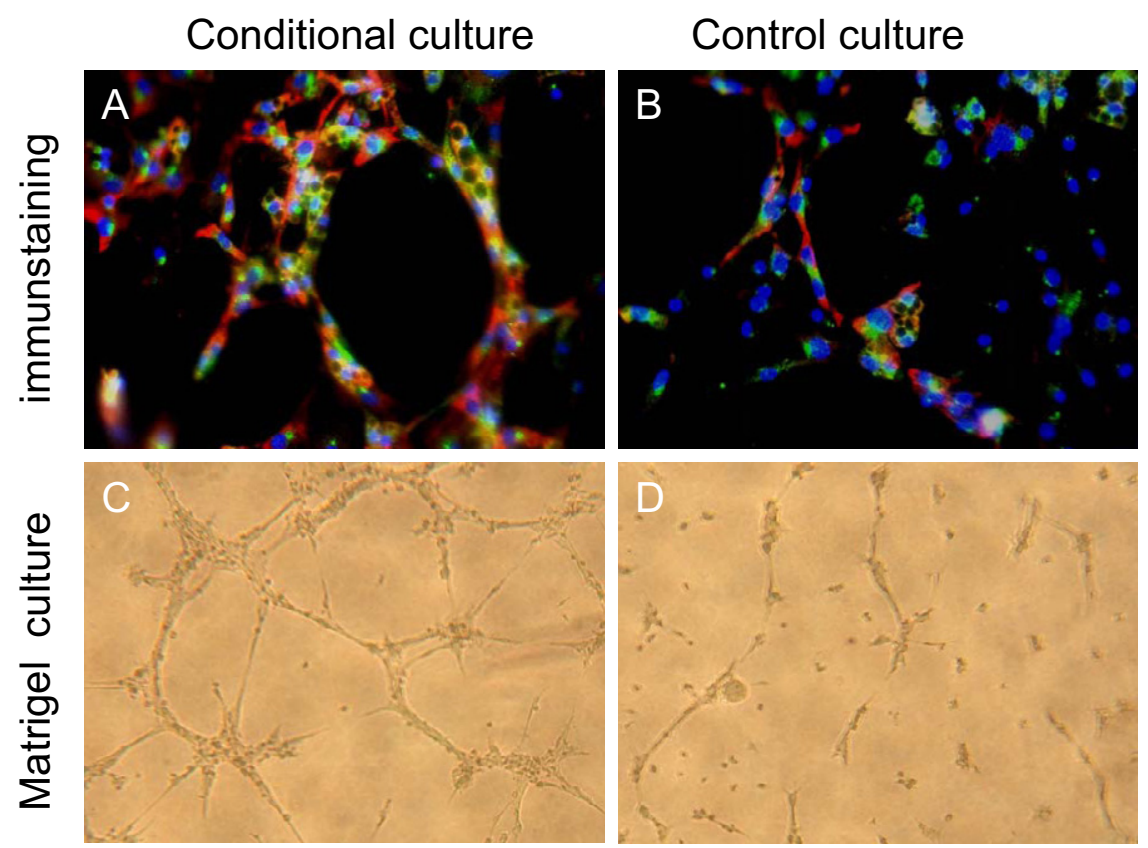

Figure 5. Retinal-cell-conditioned medium enhances EPC differentiation and tube formation in culture. Enhanced EPC cell differentiation is shown by representative immunostaining in the groups supplemented with retinal-cell-conditioned medium (A), as compared with controls without added conditioned medium (B). Red: VEGFR2 staining; green: VE-cadherin staining; blue: nuclear staining. Yellow staining denotes overlap of green and red. Tube formation of EPCs stimulated by retinal-cell-conditioned culture medium (C), as compared with controls (D). icantly increased number of CFU-EPCs in the DR patient samples than in controls. Fadini et $\mathrm{al}^{23}$ postulated that such propensity for colony formation might represent heightened differentiation efficiency of EPCs in DR; they further suggested that higher circulating EPC levels and differentiation efficiency may be related to the neovascularization in DR patients. This higher EPC level in DR contrasts to the reduced levels and dysfunction of EPCs found in systemic vasculopathies associated with types 1 and 2 DM, particularly macrovascular complications, in which vessel growth is impaired. ${ }^{15-19,21,22}$ In this study, we obtained EPC counts for only two groups: DR and normal control. Ample other studies have provided information about EPC counts in PAD-DM group. ${ }^{17,18,23,52,53}$

Neurotrophic factors are reported to be potent stimuli for new vessel growth, which may explain the unusual neovascularization in retinal vasculopathic complications of DM. We studied the systemic levels of neurotrophins

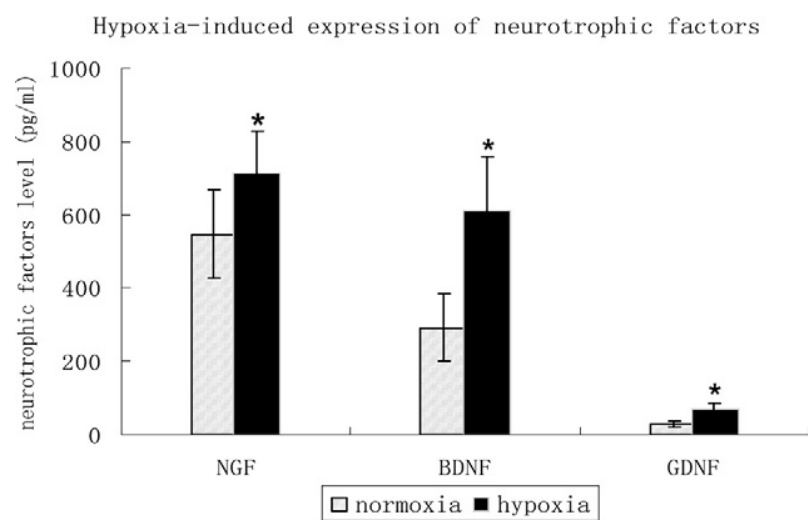

Figure 6. Increase in neurotrophin expression in retinal glia cell culture medium induced by hypoxia. Increased neurotrophin expression under hypoxic conditions included NGF, BDNF, GNDF (NGF: $545.68 \pm 120.70$ $\mathrm{pg} / \mathrm{ml}$ vs. $712.90 \pm 116.78 ; \mathrm{pg} / \mathrm{ml}$; BDNF: $292.00 \pm 92.08 \mathrm{pg} / \mathrm{ml}$ vs. $610.03 \pm$ $148.42 \mathrm{pg} / \mathrm{ml}$; GNDF: $28.94 \pm 8.29 \mathrm{pg} / \mathrm{ml}$ vs. $71.07 \pm 13.44 \mathrm{pg} / \mathrm{ml}$; as compared with the control cultures at normoxic conditions. ${ }^{*} P<0.01$.
NGF, BDNF, GDNF, and angiogenic factor VEGF, EPO, SDF-1, and explored whether such factors are correlated with EPC levels in DR patients. We found that, similar to the classic angiogenic factor VEGF, both BDNF and NGF serum concentrations were higher in DR groups than in PAD groups and nondiabetic controls. (The basic level of GDNF in serum was too low to detect.) The Spearman's rank correlation and the multiple linear regression analysis indicated that only NGF and BDNF were correlated with EPC significantly. Finally, we used logistic regression method to analyze the data with the presence of DR as the end point. Since the factors NGF and BDNF are highly correlated with EPC, we did not include them in the model to avoid multicollinearity. Two factors EPC and VEGF were shown to be significantly associated with DR. Therefore, it is tempting to speculate that signals generated by the retina in response to ischemia may stimulate activation of bone marrow EPCs, using systemic NTFs as messengers released into the circulation. It cannot be ruled out that there are other sources of NTFs.

NTFs such as NGF, BDNF, and GDNF, abundantly produced by neurons and glial cells, are well known for their role in regulating survival, growth, and functional maintenance of neuronal cells. NTFs have been described as "pleiotropic" molecules, involved in a variety of peripheral actions. ${ }^{67-70}$ NTFs alone or in combination with other biologically active molecules can impact on endothelial cells and on angiogenic activity. ${ }^{42,43}$ The application of BDNF and NGF enhanced angiogenesis markedly in vitro and in vivo. ${ }^{44-46,48,71}$ BDNF has been further shown to achieve proangiogenic effects by recruiting bone marrow-derived cell precursors. ${ }^{47,49} \mathrm{Neu}$ rotrophic factors play a functional role in reparative neovascularization. ${ }^{46,47}$ VEGF, a known angiogenic factor, also plays an important role in neuronal cell growth and survival, inducing neuritic growth and neuroprotection, particularly after ischemia. ${ }^{72-75}$ It appears that there is a 


\section{A Laser scan perfusion image}

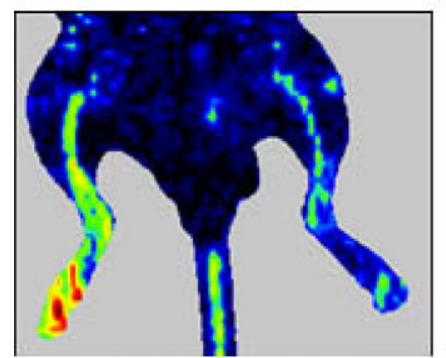

Retinal medium

\section{B CD31 immunohistochemistry staining}

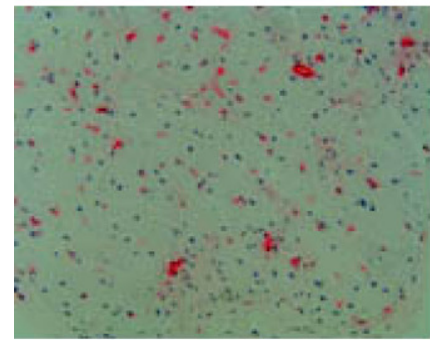

Retinal medium

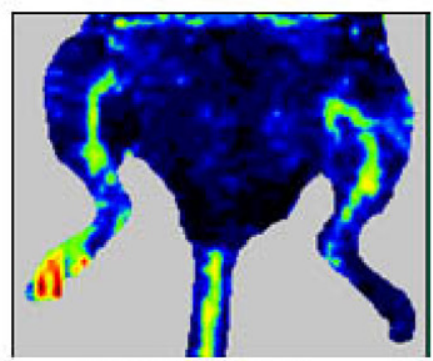

PBS control
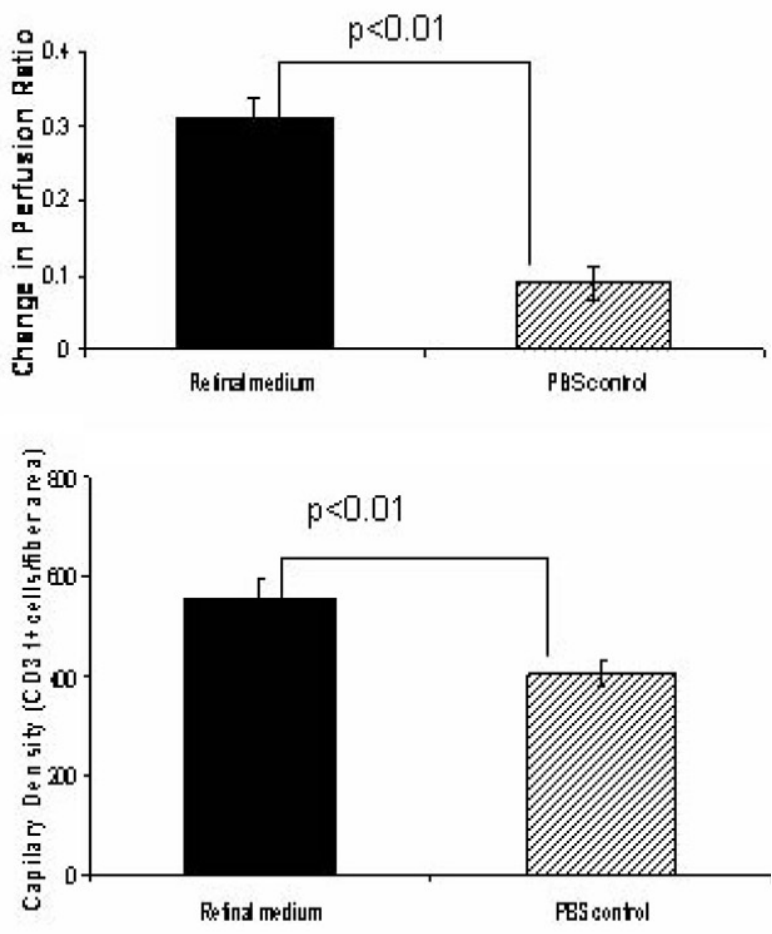

Figure 7. By 20 days after injection, retinal-cell-conditioned culture medium versus control treatment was associated with improved perfusion to the ischemic limb and increase in capillary density in ischemic gastrocnemius muscle. A: Representative photograph of the laser scan perfusion image. Changes in the perfusion ratio were calculated as the perfusion ratio at follow-up ( 20 days postinjection) minus the ratio preinjection ( 10 days post surgery, labeled day 0 ). Graphs to the right of photographs represent the quantitative assessments with $n=10$ /group for comparison. There was a marked increase in limb perfusion ratios on day 20 after injection with retinal-cell-conditioned medium versus control treatment ( $n=10$ /group ${ }^{*} P<0.01$.) B: Left, a representative CD31 immunohistochemistry staining for capillary density; red dots indicate endothelial cells (CD31 positive cells marking capillaries) (magnification $\times 200$ ). Graphs to the right of photographs represent the quantitative assessments with $n=10$ /group for all comparisons. Capillary density was increased with conditioned medium versus control treatment, ${ }^{*} P<0.01$.

dual role for these angiogenic and neural factors. Therefore, the early release of growth factors in response to ischemia in DR might be a protective reaction to maintain neuron survival, but, at the same time, such a beneficial response may, as a secondary effect, induce excessive angiogenesis in the retina.

In this study, we examined the secondary effect of NTFs as enhancers of angiogenesis and how retinal cells influence EPC activity by releasing cytokines. In our in vitro model, there was a significantly higher EPC migration rate after co-culture with retinal cells under low oxygen conditions compared with co-culture with control human microvascular endothelial cells under the same conditions. There were also significantly higher levels of differentiation of EPCs when treated with retinalcell-conditioned medium, as manifested by the expression of VEGFR2 and VE-cadherin and the observed increase in capillary-like tube formation in Matrigel culture. Our results further revealed that in hypoxic cultures, retinal cells released not only higher levels of VEGF, but also higher levels of neurotrophic factors NGF, BDNF, GDNF, which could contribute to enhancing EPC activity. Thus, we hypothesize that retinal cells enhance EPC migration and differentiation by releasing cytokines under low oxygen conditions.

We further verified the function of retinal-cellconditioned medium in promoting vessel growth in a mouse hindlimb ischemic model. The findings from the hindlimb injection experiments provide evidence that retinal tissue can release NTFs and other growth factors, and enhance angiogenesis, in this case in hindlimb muscle, non-neuronal tissue under ischemic condition. The results support the contribution of neuronal factors in angiogenesis, and provide a potential explanation why there is an enhanced angiogenesis reaction in retina in response to ischemia in diabetes patients, but an insufficient angiogenic response in ischemic limbs in diabetic milieu. Considering the multiple factors of the NTFs family, including NGF, BDNF, GDNF, NT3, NT4, and others, the precise identification of the specific factor(s) that might contribute to pathological retinal neovascularization, the assessment of the magnitude of each respective contribution, and the mechanisms of action on EC progenitors in vivo will require further substantial additional experimental work.

In addition, ischemia triggers an influx of inflammatory cells that release cytokines, proangiogenic factors, and other molecules. Moreover, the EC precursors (such as CD14+PBMCs) may contribute to angiogenesis by secreting paracrine factors. ${ }^{24-26}$ As pointed out by Schatteman GC26: "EC precursor function is governed by a plethora of systemic and local factors, and understanding molecular regulation of these cells, as always, may be much more problematic." A number of studies suggested 
that EC progenitor regulation is complex and may be mediated via direct cell-cell interactions, extracellular matrix molecules, as well as by soluble factors, including VEGF, Ang1, EPO, SDF-1, and TGF-1. The multilayered control system makes it difficult to predict the effect that any single factor will have on EC progenitors in vivo. ${ }^{24}$ On the other hand, the ischemic tissue can trigger a big influx of inflammatory cells, NTFs injection, may not significantly alter the quantity of infiltrating monocytes/macrophages and other inflammatory cells. It is also possible that the measurements may not be sensitive enough to pick up a EC precursors (such as CD14+ cell) enhancement in ischemic hindlimb muscle if such increase was of low amplitude. ${ }^{76}$

An intriguing finding in this study was the presence of higher levels of neurotrophins NGF and BDNF in peripheral blood in DR patients, but not in nondiabetic controls or DM-PAD patients. The strong correlation between neurotrophins and EPC levels in DR patients suggests that retinal ischemia serves as a signal to stimulate bone marrow EPCs through selected strong neurotrophic factors that are released into the systemic circulation. FeitLeichman et al ${ }^{77}$ postulated that diabetes-induced early changes in neurons and Muller glia contribute critically to the later development of vascular lesions in DR. Our study provides further evidence that DR may be an aberrant neovasculazation process initially driven by neurotrophins released from neuronal tissue to activate EPCs. Our data provide additional evidence that NTFs may contribute to enhanced EPC migration and differentiation in the neovasculazation that occurs in DR, representing a further and previously unveiled effect of neurotrophins on retinal neovascularization. The coordinated actions of neurotrophins and VEGF have been demonstrated in different tissues under various physiological conditions, ${ }^{45,78}$ and overexpression of NGF in brown adipose tissue of NGF-transgenic mice has been shown to elevate both mRNA and protein levels of VEGF and VEGF receptors, thus enhancing angiogenesis. ${ }^{79}$ Similarly, we propose that neovascularization in the ischemic retina might be regulated by overexpression of neurotrophins.

This study aims to demonstrate that a particular cytokine milieu is necessary for pathological retinal neovascularization. In neuronal tissues such as the retina, this particular cytokine milieu contained abundant neurotrophins, which contribute to pathological angiogenesis, which may be mediated, at least in part, through activating EC precursors. Our findings with regard to the neuronal control of angiogenesis suggest that inhibiting the angiogenic function of neurotrophins may be a new therapeutic strategy. The anti-VEGF drug bevacizumab has been recently used to treat retinal neovasculazation in clinics (in the context of macular degeneration); however, the long-term effects are not yet known. ${ }^{80}$ Our study provides new evidence that coupling anti-neurotrophic drugs with anti-VEGF antibody might be an effective approach to prevent pathological neovascularization in the retina of diabetic patients. This study provides a platform for further studying the role of neurotrophins in ischemic vasculopathies.
In conclusion, we found increased NGF and BDNF levels in the peripheral blood of DR patients, an increase that was correlated with the levels of circulating EPCs. We demonstrated that retinal cells released neurotrophic factors under low oxygen conditions to enhance EPC activity in vitro and to increase angiogenesis in a hindlimb ischemic model. These results support the concept that neurotrophic factors may induce neoangiogenesis, a process that to a degree may be reparative, but when excessive leads to pathological retinopathy. Thus, neurotrophins are growth factors with potential angiogenic actions.

\section{Acknowledgments}

Thanks go to Drs. Chunming Dong and Shoukang Zhu for their invaluable mentorship of X.L. during training years in EPC biology.

\section{References}

1. Asahara T, Murohara T, Sullivan A, Silver M, van der Zee R, Li T, Witzenbichler B, Schatteman G, Isner JM: Isolation of putative progenitor endothelial cells for angiogenesis. Science 1997, 275:964-967

2. Takahashi T, Kalka C, Masuda H, Chen D, Silver M, Kearney M, Magner M, Isner JM, Asahara T: Ischemia- and cytokine-induced mobilization of bone marrow-derived endothelial progenitor cells for neovascularization. Nat Med 1999, 5:434-438

3. Otani A, Kinder K, Ewalt K, Otero FJ, Schimmel P, Friedlander M Bone marrow-derived stem cells target retinal astrocytes and can promote or inhibit retinal angiogenesis. Nat Med 2002, 8:1004-1010

4. Grant MB, May WS, Caballero S, Brown GA, Guthrie SM, Mames RN, Byrne BJ, Vaught T, Spoerri PE, Peck AB, Scott EW: Adult hematopoietic stem cells provide functional hemangioblast activity during retinal neovascularization. Nat Med 2002, 8:607-612

5. Lee IG, Chae SL, Kim JC: Involvement of circulating endothelial progenitor cells and vasculogenic factors in the pathogenesis of diabetic retinopathy. Eye 2006, 20:546-552

6. Tamarat R, Silvestre JS, Le Ricousse-Roussanne S, Barateau V, Lecomte-Raclet L, Clergue M, Duriez M, Tobelem G, Levy BI: Impairment in ischemia-induced neovascularization in diabetes: bone marrow mononuclear cell dysfunction and therapeutic potential of placenta growth factor treatment. Am J Pathol 2004, 164:457-466

7. Butler JM, Guthrie SM, Koc M, Afzal A, Caballero S, Brooks HL, Mames RN, Segal MS, Grant MB, Scott EW: SDF-1 is both necessary and sufficient to promote proliferative retinopathy. J Clin Invest 2005, 115:86-93

8. Murasawa S, Asahara T: Endothelial progenitor cells for vasculogenesis. Physiology (Bethesda) 2005, 20:36-42

9. Kopp HG, Avecilla ST, Hooper AT, Rafii S: The bone marrow vascular niche: home of HSC differentiation and mobilization. Physiology (Bethesda) 2005, 20:349-356

10. Rafii S, Lyden D: Therapeutic stem and progenitor cell transplantation for organ vascularization and regeneration. Nat Med 2003, 9:702-712

11. Freyberger $\mathrm{H}$, Brocker M, Yakut H, Hammer J, Effert R, Schifferdecker E, Schatz H, Derwahl M: Increased levels of platelet-derived growth factor in vitreous fluid of patients with proliferative diabetic retinopathy. Exp Clin Endocrinol Diabetes 2000, 108:106-109

12. Aicher A, Zeiher AM, Dimmeler S: Mobilizing endothelial progenitor cells. Hypertension 2005, 45:321-325

13. Jin DK, Shido K, Kopp HG, Petit I, Shmelkov SV, Young LM, Hooper AT, Amano H, Avecilla ST, Heissig B, Hattori K, Zhang F, Hicklin DJ, Wu Y, Zhu Z, Dunn A, Salari H, Werb Z, Hackett NR, Crystal RG, Lyden D, Rafii S: Cytokine-mediated deployment of SDF-1 induces revascularization through recruitment of CXCR4+ hemangiocytes. Nat Med 2006, 12:557-567

14. Watanabe D, Suzuma K, Matsui S, Kurimoto M, Kiryu J, Kita M, Suzuma I, Ohashi H, Ojima T, Murakami T, Kobayashi T, Masuda S, 
Nagao M, Yoshimura N, Takagi H: Erythropoietin as a retinal angiogenic factor in proliferative diabetic retinopathy. N Engl J Med 2005, 353:782-792

15. Tepper OM, Galiano RD, Capla JM, Kalka C, Gagne PJ, Jacobowitz GR, Levine JP, Gurtner GC: Human endothelial progenitor cells from type II diabetics exhibit impaired proliferation, adhesion, and incorporation into vascular structures. Circulation 2002, 106:2781-2786

16. Loomans CJ, de Koning EJ, Staal FJ, Rookmaaker MB, Verseyden C, de Boer HC, Verhaar MC, Braam B, Rabelink TJ, van Zonneveld AJ: Endothelial progenitor cell dysfunction: a novel concept in the pathogenesis of vascular complications of type 1 diabetes. Diabetes 2004 53:195-199

17. Fadini GP, Miorin M, Facco M, Bonamico S, Baesso I, Grego F, Menegolo M, de Kreutzenberg SV, Tiengo A, Agostini C, Avogaro A: Circulating endothelial progenitor cells are reduced in peripheral vascular complications of type 2 diabetes mellitus. J Am Coll Cardiol 2005, 45:1449-1457

18. Fadini GP, Sartore S, Albiero M, Baesso I, Murphy E, Menegolo M, Grego F, Vigili de Kreutzenberg S, Tiengo A, Agostini C, Avogaro A: Number and function of endothelial progenitor cells as a marker of severity for diabetic vasculopathy. Arterioscler Thromb Vasc Biol 2006, 26:2140-2146

19. Chen YH, Lin SJ, Lin FY, Wu TC, Tsao CR, Huang PH, Liu PL, Chen $Y L$, Chen JW: High glucose impairs early and late endothelial progenitor cells by modifying nitric oxide-related but not oxidative stressmediated mechanisms. Diabetes 2007, 56:1559-1568

20. Hill JM, Zalos G, Halcox JP, Schenke WH, Waclawiw MA, Quyyumi AA, Finkel T: Circulating endothelial progenitor cells, vascular function, and cardiovascular risk. N Engl J Med 2003, 348:593-600

21. Vasa M, Fichtlscherer S, Aicher A, Adler K, Urbich C, Martin H, Zeiher AM, Dimmeler S: Number and migratory activity of circulating endothelial progenitor cells inversely correlate with risk factors for coronary artery disease. Circ Res 2001, 89:E1-E7

22. Waltenberger J: Impaired collateral vessel development in diabetes: potential cellular mechanisms and therapeutic implications. Cardiovasc Res 2001, 49:554-560

23. Fadini GP, Sartore S, Baesso I, Lenzi M, Agostini C, Tiengo A, Avogaro A: Endothelial progenitor cells and the diabetic paradox. Diabetes Care 2006, 29:714-716

24. Wang C, Jiao C, Hanlon HD, Zheng W, Tomanek RJ, Schatteman GC: Mechanical, cellular, and molecular factors interact to modulate circulating endothelial cell progenitors. Am J Physiol Heart Circ Physiol 2004, 286:H1985-H1993

25. Awad O, Dedkov El, Jiao C, Bloomer S, Tomanek RJ, Schatteman GC: Differential healing activities of CD34+ and CD14+ endothelial cell progenitors. Arterioscler Thromb Vasc Biol 2006, 26:758-764

26. Schatteman GC, Dunnwald M, Jiao C: Biology of bone marrowderived endothelial cell precursors. Am J Physiol Heart Circ Physiol 2007, 292:H1-H18

27. Duda DG, Jain RK: Pleiotropy of tissue-specific growth factors: from neurons to vessels via the bone marrow. J Clin Invest 2005, 115:596-598

28. West H, Richardson WD, Fruttiger M: Stabilization of the retinal vascular network by reciprocal feedback between blood vessels and astrocytes. Development 2005, 132:1855-1862

29. Suchting S, Bicknell R, Eichmann A: Neuronal clues to vascular guidance. Exp Cell Res 2006, 312:668-675

30. Carmeliet P, Tessier-Lavigne M: Common mechanisms of nerve and blood vessel wiring. Nature 2005, 436:193-200

31. Vogel G: Developmental biology. The unexpected brains behind blood vessel growth. Science 2005, 307:665-667

32. Eichmann A, Makinen T, Alitalo K: Neural guidance molecules regulate vascular remodeling and vessel navigation. Genes Dev 2005, 19:1013-1021

33. Mukouyama YS, Shin D, Britsch S, Taniguchi M, Anderson DJ: Sensory nerves determine the pattern of arterial differentiation and blood vessel branching in the skin. Cell 2002, 109:693-705

34. Gerhardt H, Golding M, Fruttiger M, Ruhrberg C, Lundkvist A, Abramsson A, Jeltsch M, Mitchell C, Alitalo K, Shima D, Betsholtz C: VEGF guides angiogenic sprouting utilizing endothelial tip cell filopodia. J Cell Biol 2003, 161:1163-1177

35. Eichler W, Kuhrt H, Hoffmann S, Wiedemann P, Reichenbach A: VEGF release by retinal glia depends on both oxygen and glucose supply. Neuroreport 2000, 11:3533-3537
36. Eichler W, Yafai $Y$, Kuhrt H, Grater R, Hoffmann S, Wiedemann P, Reichenbach A: Hypoxia: modulation of endothelial cell proliferation by soluble factors released by retinal cells. Neuroreport 2001, 12:4103-4108

37. Ijichi A, Sakuma S, Tofilon PJ: Hypoxia-induced vascular endothelial growth factor expression in normal rat astrocyte cultures. Glia 1995, 14:87-93

38. Aicher A, Heeschen C, Mildner-Rihm C, Urbich C, Ihling C, TechnauIhling K, Zeiher AM, Dimmeler S: Essential role of endothelial nitric oxide synthase for mobilization of stem and progenitor cells. Nat Med 2003, 9:1370-1376

39. Asahara T, Takahashi T, Masuda H, Kalka C, Chen D, Iwaguro H, Inai Y, Silver M, Isner JM: VEGF contributes to postnatal neovascularization by mobilizing bone marrow-derived endothelial progenitor cells. EMBO J 1999, 18:3964-3972

40. Hattori K, Dias S, Heissig B, Hackett NR, Lyden D, Tateno M, Hicklin DJ, Zhu Z, Witte L, Crystal RG, Moore MA, Rafii S: Vascular endothelial growth factor and angiopoietin-1 stimulate postnatal hematopoiesis by recruitment of vasculogenic and hematopoietic stem cells. $J$ Exp Med 2001, 193:1005-1014

41. Torres-Vazquez J, Gitler AD, Fraser SD, Berk JD, Van NP, Fishman MC, Childs S, Epstein JA, Weinstein BM: Semaphorin-plexin signaling guides patterning of the developing vasculature. Dev Cell 2004, 7:117-123

42. Donovan MJ, Lin MI, Wiegn P, Ringstedt T, Kraemer R, Hahn R, Wang S, Ibanez CF, Rafii S, Hempstead BL: Brain derived neurotrophic factor is an endothelial cell survival factor required for intramyocardial vessel stabilization. Development 2000, 127:4531-4540

43. Calza L, Giardino L, Giuliani A, Aloe L, Levi-Montalcini R: Nerve growth factor control of neuronal expression of angiogenetic and vasoactive factors. Proc Natl Acad Sci USA: 2001;98:4160-4165

44. Turrini P, Gaetano C, Antonelli A, Capogrossi MC, Aloe L: Nerve growth factor induces angiogenic activity in a mouse model of hindlimb ischemia. Neurosci Lett 2002, 323:109-112

45. Cantarella G, Lempereur L, Presta M, Ribatti D, Lombardo G, Lazarovici P, Zappala G, Pafumi C, Bernardini R: Nerve growth factor-endothelial cell interaction leads to angiogenesis in vitro and in vivo. FASEB J 2002, 16:1307-1309

46. Emanueli C, Salis MB, Pinna A, Graiani G, Manni L, Madeddu P: Nerve growth factor promotes angiogenesis and arteriogenesis in ischemic hindlimbs. Circulation 2002, 106:2257-2262

47. Emanueli C, Bonaria Salis M, Stacca T, Pintus G, Kirchmair R, Isner JM, Pinna A, Gaspa L, Regoli D, Cayla C, Pesquero JB, Bader M, Madeddu P: Targeting kinin B(1) receptor for therapeutic neovascuIarization. Circulation 2002, 105:360-366

48. Wilson BD, li M, Park KW, Suli A, Sorensen LK, Larrieu-Lahargue F, Urness LD, Suh W, Asai J, Kock GA, Thorne T, Silver M, Thomas KR, Chien CB, Losordo DW, Li DY: Netrins promote developmental and therapeutic angiogenesis. Science 2006, 313:640-644

49. Kermani P, Rafii D, Jin DK, Whitlock P, Schaffer W, Chiang A, Vincent L, Friedrich M, Shido K, Hackett NR, Crystal RG, Rafii S, Hempstead BL: Neurotrophins promote revascularization by local recruitment of TrkB + endothelial cells and systemic mobilization of hematopoietic progenitors. J Clin Invest 2005, 115:653-663

50. Del Papa N, Colombo G, Fracchiolla N, Moronetti LM, Ingegnoli F, Maglione W, Comina DP, Vitali C, Fantini F, Cortelezzi A: Circulating endothelial cells as a marker of ongoing vascular disease in systemic sclerosis. Arthritis Rheum 2004, 50:1296-1304

51. Milkiewicz M, Ispanovic E, Doyle JL, Haas TL: Regulators of angiogenesis and strategies for their therapeutic manipulation. Int J Biochem Cell Biol 2006, 38:333-357

52. Hughes AD, Coady E, Raynor S, Mayet J, Wright AR, Shore AC, Kooner JS, Thom SA, Chaturvedi N: Reduced endothelial progenitor cells in European and South Asian men with atherosclerosis. Eur J Clin Invest 2007, 37:35-41

53. Lachmann N, Nikol S: Therapeutic angiogenesis for peripheral artery disease: stem cell therapy. Vasa 2007, 36:241-251

54. Lyons TJ, Jenkins AJ, Zheng D, Lackland DT, McGee D, Garvey WT, Klein RL: Diabetic retinopathy and serum lipoprotein subclasses in the DCCT/EDIC cohort. Invest Ophthalmol Vis Sci 2004, 45:910-918

55. Powell TM, Paul JD, Hill JM, Thompson M, Benjamin M, Rodrigo M, McCoy JP, Read EJ, Khuu HM, Leitman SF, Finkel T, Cannon RO, 3rd: Granulocyte colony-stimulating factor mobilizes functional endothelial 
progenitor cells in patients with coronary artery disease. Arterioscler Thromb Vasc Biol 2005, 25:296-301

56. Guven H, Shepherd RM, Bach RG, Capoccia BJ, Link DC: The number of endothelial progenitor cell colonies in the blood is increased in patients with angiographically significant coronary artery disease. J Am Coll Cardiol 2006, 48:1579-1587

57. Hur J, Yoon CH, Kim HS, Choi JH, Kang HJ, Hwang KK, Oh BH, Lee MM, Park YB: Characterization of two types of endothelial progenitor cells and their different contributions to neovasculogenesis. Arterioscler Thromb Vasc Biol 2004, 24:288-293

58. Lin Y, Weisdorf DJ, Solovey A, Hebbel RP: Origins of circulating endothelial cells and endothelial outgrowth from blood. J Clin Invest 2000, 105:71-77

59. Aotaki-Keen AE, Harvey AK, de Juan E, Hjelmeland LM: Primary culture of human retinal glia. Invest Ophthalmol Vis Sci 1991, 32:1733-1738

60. Guidry C: Isolation and characterization of porcine Muller cells. Myofibroblastic dedifferentiation in culture. Invest Ophthalmol Vis Sci 1996, 37:740-752

61. Umapathy NS, Li W, Mysona BA, Smith SB, Ganapathy V: Expression and function of glutamine transporters SN1 (SNAT3) and SN2 (SNAT5) in retinal Muller cells. Invest Ophthalmol Vis Sci 2005, 46:3980-3987

62. Jingjing L, Xue Y, Agarwal N, Roque RS: Human Muller cells express VEGF183, a novel spliced variant of vascular endothelial growth factor. Invest Ophthalmol Vis Sci 1999, 40:752-759

63. Oh J, Seo DW, Diaz T, Wei B, Ward Y, Ray JM, Morioka Y, Shi S, Kitayama H, Takahashi C, Noda M, Stetler-Stevenson WG: Tissue inhibitors of metalloproteinase 2 inhibits endothelial cell migration through increased expression of RECK. Cancer Res 2004, 64:9062-9069

64. Aznavoorian S, Stracke ML, Krutzsch H, Schiffmann E, Liotta LA Signal transduction for chemotaxis and haptotaxis by matrix molecules in tumor cells. J Cell Biol 1990, 110:1427-1438

65. Zhu S, Liu X, Li Y, Goldschmidt-Clermont PJ, Dong C: Aging in the atherosclerosis milieu may accelerate the consumption of bone marrow endothelial progenitor cells. Arterioscler Thromb Vasc Biol 2007, 27:113-119

66. Li Y, Hazarika S, Xie D, Pippen AM, Kontos CD, Annex BH: In mice with type 2 diabetes, a vascular endothelial growth factor (VEGF)activating transcription factor modulates VEGF signaling and induces therapeutic angiogenesis after hindlimb ischemia. Diabetes 2007, $56: 656-665$

67. Aloe L, Simone MD, Properzi F: Nerve growth factor: a neurotrophin with activity on cells of the immune system. Microsc Res Tech 1999, 45:285-291
68. Lambiase A, Rama P, Bonini S, Caprioglio G, Aloe L: Topical treatment with nerve growth factor for corneal neurotrophic ulcers. N Engl J Med 1998, 338:1174-1180

69. Bernabei R, Landi F, Bonini S, Onder G, Lambiase A, Pola R, Aloe L: Effect of topical application of nerve-growth factor on pressure ulcers. Lancet 1999, 354:307

70. Ransohoff RM, Trebst C: Surprising pleiotropy of nerve growth factor in the treatment of experimental autoimmune encephalomyelitis. J Exp Med 2000, 191:1625-1630

71. Nakamura K, Martin KC, Jackson JK, Beppu K, Woo CW, Thiele CJ: Brain-derived neurotrophic factor activation of TrkB induces vascular endothelial growth factor expression via hypoxia-inducible factor1alpha in neuroblastoma cells. Cancer Res 2006, 66:4249-4255

72. Sondell M, Lundborg G, Kanje M: Vascular endothelial growth factor stimulates Schwann cell invasion and neovascularization of acellular nerve grafts. Brain Res 1999, 846:219-228

73. Sondell M, Lundborg G, Kanje M: Vascular endothelial growth factor has neurotrophic activity and stimulates axonal outgrowth, enhancing cell survival and Schwann cell proliferation in the peripheral nervous system. J Neurosci 1999, 19:5731-5740

74. Sondell M, Sundler F, Kanje M: Vascular endothelial growth factor is a neurotrophic factor which stimulates axonal outgrowth through the flk-1 receptor. Eur J Neurosci 2000, 12:4243-4254

75. Samii A, Unger J, Lange W: Vascular endothelial growth factor expression in peripheral nerves and dorsal root ganglia in diabetic neuropathy in rats. Neurosci Lett 1999, 262:159-162

76. Schatteman GC, Hanlon HD, Jiao C, Dodds SG, Christy BA: Bloodderived angioblasts accelerate blood-flow restoration in diabetic mice. J Clin Invest 2000, 106:571-578

77. Feit-Leichman RA, Kinouchi R, Takeda M, Fan Z, Mohr S, Kern TS, Chen DF: Vascular damage in a mouse model of diabetic retinopathy: relation to neuronal and glial changes. Invest Ophthalmol Vis Sci 2005, 46:4281-4287

78. Li Q, Ford MC, Lavik EB, Madri JA: Modeling the neurovascular niche: VEGF- and BDNF-mediated cross-talk between neural stem cells and endothelial cells: an in vitro study. J Neurosci Res 2006, 84:1656-1668

79. Hansen-Algenstaedt N, Algenstaedt P, Schaefer C, Hamann A, Wolfram L, Cingoz G, Kilic N, Schwarzloh B, Schroeder M, Joscheck C, Wiesner L, Ruther W, Ergun S: Neural driven angiogenesis by overexpression of nerve growth factor. Histochem Cell Biol 2006, 125:637-649

80. Jorge R, Costa RA, Calucci D, Cintra LP, Scott IU: Intravitreal bevacizumab (Avastin) for persistent new vessels in diabetic retinopathy (IBEPE study). Retina 2006, 26:1006-1013 